\section{Prospective controlled study of psychiatric out-patient non-attendance}

\author{
Characteristics and outcome
}

HELEN KILLASPY, SUBE BANERJEE, MICHAEL KING and MARGARET LLOYD

\author{
Background Psychiatric clinics have \\ high non-attendance rates and failure to \\ attend may be a sign of deteriorating \\ mental health.
}

\begin{abstract}
Aims To investigate why psychiatric outpatients fail to attend, and the outcome of attenders and non-attenders.
\end{abstract}

\begin{abstract}
Method Prospective cohort study of randomly selected attenders and nonattenders at general adult psychiatric outpatient clinics. Subjects were interviewed at recruitment and severity of mental disorder and degree of social adjustment were measured. Six and 12 months later their engagement with the clinic and any psychiatric admissions were ascertained.
\end{abstract}

Results Of the 365 patients included in the study, 30 were untraceable and 224 consented to participate. Follow-up patients were more psychiatrically unwell than new patients. For follow-up patients, non-attenders had lower social functioning and more severe mental disorder than those who attended. At 12-month follow-up patients who missed their appointment were more likely to have been admitted than those who attended.

\section{Conclusions Those who miss psychiatric follow-up out-patient appointments are more unwell and more poorly socially functioning than those who attend. They have a greater chance of drop-out from clinic contact and subsequent admission.}

\author{
Declaration of interest Funding \\ from the NHS Executive.
}

Out-patient non-attendance is a serious problem in clinical and economic terms. In psychiatry there is the particular concern that non-attendance and subsequent loss to follow-up can represent a deterioration in mental state and therefore indicate possible risk of harm to the patient or to others (Ritchie et al, 1994; Steering Committee of the Confidential Inquiry into Homicides and Mentally Ill People, 1996). Newly discharged patients who do not attend followup have been reported to have a two- to three-fold increase in the rate of readmission compared with those who remain in contact with services (Koch \& Gillis, 1991). Despite this and the finding that the rate of non-attendance at psychiatric clinics is twice that of most other specialities (Jones, 1987; McGlade et al, 1988), there has been little research into the reasons for this and its consequences. Such information is needed if effective strategies to prevent non-attendance are to be formulated and an appropriate response to nonattendance is to be mounted. We therefore carried out a prospective controlled study to investigate why psychiatric patients miss their appointments and what the consequences are of non-attendance.

\section{METHOD}

\section{Subjects}

The sampling frame consisted of all patients aged 18-65 years, living in North Camden, an inner-London psychiatric catchment area, who had a general adult psychiatric out-patient appointment between September 1996 and April 1997. Pre-study power calculations indicated that 75 subjects were required in each group to test differences between attenders and non-attenders. The protocol was approved by the local research ethics committee.

Subjects were randomly selected by computer-generated random number with sampling fractions calculated on the basis of the previous six months' out-patient activity. The sampling fractions were: new patient non-attenders 1:1; new patient attenders 1:3; follow-up non-attenders 1:7, and follow-up attenders 1:12. Patients whose appointments were cancelled were not included in the study. Each subject was assigned to one of the four groups according to status at their first appointment during the study period. Subjects with more than one appointment in the study period were defined by their first appointment and excluded from consideration thereafter.

\section{Recruitment}

Recruitment is a particular problem when investigating those who by definition have defaulted from their treatment plan. We therefore designed the study to attempt to contact as many of the selected subjects as possible to minimise non-response bias. We wrote to each subject with an appointment for a home interview and a researcher (H.K.) visited them if they had not declined consent. If contact was not made on this visit, then further telephone and postal communication was attempted to reschedule the interview. If there was still no response, we made a second home visit without an appointment. Finally, a postal questionnaire was sent to subjects we had not managed to interview.

\section{Information collected}

A clinical diagnosis was made from case note data using the ICD-10 (World Health Organization, 1992) for all those randomised for entry into the study. Age and gender data were also collected on all subjects. A semi-structured interview was completed with subjects who agreed to participate at which socio-demographic data and past psychiatric history were gathered. Severity of mental disorder was assessed using the Manchester Scale (Krawiecka et al, 1977) which rates eight major psychiatric symptoms as either absent (scoring zero) or present from a mild to a severe degree (scoring 1-4) and may be particularly appropriate for people with psychosis. Level of social disorganisation was assessed using the Social Adjustment Scale (Marks, 1986). This rates degree of impairment attributed to psychiatric problems in each of four areas (home management, work, social leisure activities and private leisure activities) on a scale from 1-8; the higher the score, the greater the impairment. 
In addition, new referrals were asked: who had referred them; whether the referrer had clearly explained the reasons for referral; whether their general practitioner (GP) had prescribed medication for the problem; the time from referral to receiving the appointment; and whether they had told anybody about the referral. Follow-up patients were asked about their current contact with the clinic and the grade of doctor they saw. Non-attenders were asked why they had missed their appointment.

\section{Outcome data}

Six and twelve months after recruitment, admission data and case notes were examined to assess each subject's out-patient contact and whether they had been admitted to hospital. Outcome data were collected on all subjects randomised for entry into the study irrespective of whether they were interviewed.

\section{Statistical analysis}

Statistical analysis was carried out using SPSS 7.0. Chi-squared and Mann-Whitney $U$-tests were used to investigate differences between attenders and non-attenders, new patients and follow-ups, with the $P$ value for statistical significance set at 0.05 . Student's $t$-test was used to examine differences in age between groups.

\section{RESULTS}

\section{Response}

During the study period a total of 1678 follow-up appointments were attended and 982 were not (a follow-up nonattendance rate of $40 \%$ ). Of the new patient appointments 105 were attended and 59 were missed (a non-attendance rate for new referrals of $36 \%$ ).

Three hundred and sixty-five patients were randomly selected for entry into the study. Twelve $(20 \%)$ new patient nonattenders and 15 (12\%) follow-up nonattenders could not be traced despite exhaustive search. Their home addresses were boarded up or clearly uninhabited, or those living at the address had never heard of them and other sources (including their GP and social services) had no alternative address for them. Two hundred and twenty-four patients consented to participate (a response rate of $66 \%$ of those traceable and $61 \%$ overall) of whom 12 $(5 \%)$ completed postal questionnaires.

Table I Recruitment and response rates

\begin{tabular}{|c|c|c|c|c|c|}
\hline Study group & $\begin{array}{c}\text { Population } \\
\text { randomly } \\
\text { selected }\end{array}$ & $\begin{array}{c}\text { Total } \\
\text { untraceable }\end{array}$ & Interviewed & $\begin{array}{c}\text { Response rate } \\
\text { overall (\%) }\end{array}$ & $\begin{array}{l}\text { Response rate } \\
\text { of those } \\
\text { traceable (\%) }\end{array}$ \\
\hline New patient non-attenders & 59 & 12 & 29 & 49 & 62 \\
\hline New patient attenders & 41 & 0 & 28 & 68 & 68 \\
\hline Follow-up non-attenders & 129 & 15 & 76 & 59 & 67 \\
\hline Follow-up attenders & 136 & 1 & 91 & 67 & 67 \\
\hline Total & 365 & 28 & 224 & 61 & 66 \\
\hline
\end{tabular}

Table 2 Primary diagnosis of new patients and follow-up patients

\begin{tabular}{lccrr}
\hline Primary diagnosis & $\begin{array}{c}\text { New patients } \\
n=57(\%)\end{array}$ & $\begin{array}{c}\text { Follow-up patients } \\
n=167(\%)\end{array}$ & $\chi^{2}$ & $P$ \\
\hline Depressive disorder & $30(53)$ & $43(26)$ & 13.3 & $<0.001$ \\
Anxiety disorder & $12(2 \mathrm{I})$ & $16(10)$ & 21.6 & $<0.00 \mathrm{I}$ \\
Bipolar affective disorder & $3(5)$ & $30(18)$ & 4.7 & 0.031 \\
Schizophrenia or schizoaffective disorder & $2(4)$ & $63(38)$ & 8.8 & 0.003 \\
Substance misuse only & $4(7)$ & $4(2)$ & 5.9 & 0.015 \\
Personality disorder only & $3(5)$ & $\mathrm{II}(7)$ & 0.2 & 0.700 \\
No psychiatric illness & $3(5)$ & $0(0)$ & 11.8 & $<0.00 \mathrm{I}$ \\
\hline
\end{tabular}

Recruitment and response rates are summarised in Table 1 .

\section{Socio-demographic data}

Of the 224 subjects interviewed, 173 (78\%) described their ethnic group as White European and the mean age was 39 years. The rate of unemployment in the study population was $83 \%$ (95\% confidence interval (95\% CI) $78.1-88.0$ ) compared with $12 \%$ for the general population in North Camden. There was no statistically significant difference between the four study groups in socio-demographic characteristics. Twenty-four (14\%) follow-up patients had no social support other than from mental health professionals compared with only one $(2 \%)$ of the new patient group $\left(\chi^{2}=5.61 ;\right.$ d.f. $\left.=1, P=0.018\right)$. There was no gender difference between non-responders (including subjects who refused consent, those who were untraceable and those who made no response) and subjects interviewed. However, non-responders were younger than those who took part in the study (mean age 36 (s.d.=12) v. 39 (s.d. $=12$ ) years, Student's $t$-test: $P=0.005$, $95 \%$ CI of the difference 6.23-1.09).

\section{Primary diagnosis}

There were marked differences between new patients and follow-up patients in terms of diagnosis and severity of disorder. New patients predominantly had primary diagnoses of depression and anxiety, whereas follow-up patients were more likely than new patients to have a diagnosis of schizophrenia or bipolar affective disorder (see Table 2). There were no statistically significant differences between nonresponders and those interviewed other than that there was a lower prevalence of bipolar affective disorder among the follow-up non-responders compared with those in the follow-up group who were interviewed $\left(5(5 \%) v .30(18 \%) ; \chi^{2}=8.91\right.$, d.f. $=1, P=0.003)$.

\section{Mental state and social functioning}

Table 3 presents details of subjects' mental health as measured by the Manchester Scale and Table 4 social functioning as measured by the Social Adjustment Scale. Follow-up patients were more psychiatrically ill than new patients (Mann-Whitney $U$-test, $P=0.046$ ) and follow-up non-attenders scored significantly higher for both mental 
disorder and social impairment than follow-up attenders (Manchester Scale Mann-Whitney $U$-test, $P=0.031$; Social Adjustment Scale Mann-Whitney $U$-test, $P=0.018$ ).

\section{New patients}

Seventy-three per cent of new patients were referred by their GP and the remainder by hospital doctors. More attenders had agreed to the referral compared with nonattenders $(25 \quad(89 \%) \quad v .20 \quad(69 \%)$, $\chi^{2}=3.54$, d.f. $\left.=1, P=0.06\right)$. Most attenders $(93 \%)$ and non-attenders $(86 \%)$ felt that the reason for referral had been clearly explained to them. Attenders were more likely than non-attenders to have been prescribed psychotropic medication by their GP prior to the referral $(20(71 \%) v .11(38 \%)$, $\chi^{2}=6.44$, d.f. $=1, P=0.011$ ). There were no statistically significant differences between attenders and non-attenders in having told somebody about the referral and in rates of previous contact with psychiatric services. Non-attenders had waited no longer for their appointment than attenders, with
$73 \%$ of appointments occurring within four weeks of referral.

\section{Follow-up patients}

Non-attendance was associated with a previous history of admission under the Mental Health Act 1983 (38 (50\%) v. 31 (34\%), $\chi^{2}=4.34$, d.f. $\left.=1, P=0.037\right)$. There was no statistically significant difference between attenders and non-attenders in the length of time they had been under the care of the out-patient department, who they were seen by or how often they were seen.

\section{Non-attenders}

Forgetting the appointment $(27 \%)$ and being too psychiatrically unwell $(14 \%)$ were the most common reasons given for non-attendance by the follow-up patients, while being unhappy with the referral $(17 \%)$, clerical error $(14 \%)$ and being too unwell $(14 \%)$ were the most common reasons in the new patient group. Further details are presented in Table 5 .

\section{Outcome at six and 12 months}

Twelve months after recruitment into the study those follow-up patients who had missed their appointment had a much higher chance of admission than those who had attended the clinic at entry to the study (42 (33\%) non-attenders $v .27(20 \%)$ attenders, $\chi^{2}=5.55$, d.f. $\left.=1, P=0.018\right)$. This difference was not apparent at the six-month follow-up point (24 (19\%) attenders $v .23$ $(17 \%)$ non-attenders, $\chi^{2}=0.13$, d.f. $=1$, $P=0.72$ ).

Ninety-two (68\%) follow-up attenders were still attending the clinic after six months compared with 47 (36\%) followup non-attenders $\left(\chi^{2}=25.9, \quad\right.$ d.f. $=1$, $P<0.001)$ and by twelve months these figures had barely altered $(97(71 \%) v .46$ $(36 \%))$.

At twelve months there were few admissions among the new patients (two attenders and two non-attenders). At six months $18(44 \%)$ new patient attenders were still in contact with the clinic compared with four $(7 \%)$ new patient nonattenders $\left(\chi^{2}=17.3\right.$, d.f. $\left.=1, P<0.001\right)$ and this difference persisted at twelve months

Table 3 Distribution of severity of mental disorder between out-patient attenders and non-attenders

\begin{tabular}{|c|c|c|c|c|c|c|c|}
\hline \multirow[t]{2}{*}{ Study group } & \multirow[t]{2}{*}{ Mean $(95 \% \mathrm{Cl})$} & \multicolumn{5}{|c|}{ Manchester Scale score } & \multirow[t]{2}{*}{ Mann-Whitney test } \\
\hline & & 0 & $\mathrm{I}-8$ & $9-16$ & $17-24$ & $25-32$ & \\
\hline All new patients, $n=54(\%)$ & $2.94(2.39-3.49)$ & $7(13)$ & $47(87)$ & 0 & 0 & 0 & \multirow{2}{*}{$P=0.046$} \\
\hline All follow-up patients, $n=155(\%)$ & $4.74(4.04-5.44)$ & $29(19)$ & $97(63)$ & $25(16)$ & $4(2)$ & 0 & \\
\hline New patient non-attenders, $n=27$ (\%) & $2.93(2.16-3.69)$ & $3(I I)$ & $24(89)$ & 0 & 0 & 0 & \multirow{2}{*}{$P=0.965$} \\
\hline New patient attenders, $n=27$ (\%) & $2.96(2.12-3.80)$ & $4(15)$ & $23(85)$ & 0 & 0 & 0 & \\
\hline Follow-up non-attenders, $n=71$ (\%) & $5.48(4.44-6.52)$ & $10(14)$ & $43(61)$ & $17(24)$ & I (I) & 0 & \multirow{2}{*}{$P=0.031$} \\
\hline Follow-up attenders, $n=84$ (\%) & $4.11(3.16-5.15)$ & $19(23)$ & $54(64)$ & $8(10)$ & $3(4)$ & 0 & \\
\hline
\end{tabular}

Table 4 Distribution of impairment in social functioning between out-patient attenders and non-attenders

\begin{tabular}{|c|c|c|c|c|c|c|c|}
\hline \multirow[t]{2}{*}{ Study group } & \multirow[t]{2}{*}{ Mean $(95 \% \mathrm{Cl})$} & \multicolumn{5}{|c|}{ Social Adjustment Scale score } & \multirow[t]{2}{*}{ Mann-Whitney test } \\
\hline & & 0 & $\mathrm{I}-8$ & $9-16$ & $17-24$ & $25-32$ & \\
\hline All new patients, $n=57(\%)$ & $10.69(8.32-13.05)$ & $9(16)$ & $20(35)$ & $12(2 I)$ & $12(2 \mid)$ & $4(7)$ & \multirow{2}{*}{$P=0.366$} \\
\hline All follow-up patients, $n=167$ (\%) & $11.96(10.57-13.35)$ & $23(14)$ & $4 \mathrm{I}(25)$ & $5 I(3 I)$ & $36(22)$ & $16(10)$ & \\
\hline New patient non-attenders, $n=29(\%)$ & $9.78(6.44-13.12)$ & $6(2 I)$ & $10(34)$ & $7(24)$ & $3(10)$ & $3(10)$ & \multirow{2}{*}{$P=0.554$} \\
\hline New patient attenders, $n=28(\%)$ & $11.59(8.06-15.12)$ & $3(\mathrm{II})$ & $10(36)$ & $5(18)$ & $9(32)$ & I (4) & \\
\hline Follow-up non-attenders, $n=76(\%)$ & $13.58(\mid 1.52-15.64)$ & $8(I I)$ & $14(18)$ & $26(34)$ & $18(24)$ & $10(13)$ & \multirow{2}{*}{$P=0.018$} \\
\hline Follow-up attenders, $n=91$ (\%) & $10.6(8.73-12.46)$ & $15(16)$ & $27(30)$ & $25(27)$ & $18(20)$ & $6(7)$ & \\
\hline
\end{tabular}


(19 (46\%) attenders $v .8$ (14\%) non-attenders). Outcome data for the four study groups are presented in Table 6.

\section{DISCUSSION}

The most striking findings of this study are that follow-up psychiatric patients have more severe mental health problems than new patients, and those who miss appointments are more unwell, more socially impaired and have a higher chance of subsequent admission than those who attend. A single missed appointment predicts drop-out from the clinic for both new and follow-up patients but this has more serious implications for the follow-up population.

\section{Limitations}

This study is the first to provide systematic, prospective data comparing the nature of attenders and non-attenders at a psychiatric out-patient clinic. However, since it was carried out in a single inner-city area there may be limitations in generalising the results beyond similar populations with similar models of service provision. Nevertheless, the inner city is of particular clinical and policy interest since high morbidity, high need and failures of community care have been identified (Ritchie et al, 1994; Johnson \& Lelliott, 1997). The out-patient setting was chosen as it has less variability than other elements of mental health service provision and remains the most common model used for monitoring patients in the community.

Table 5 Reasons given by non-attenders for missing their appointments

\begin{tabular}{lcc}
\hline Reason for missing appointment & $\begin{array}{c}\text { Follow-up non-attenders } \\
n=74(\%)\end{array}$ & $\begin{array}{c}\text { New patient non-attenders } \\
n=29(\%)\end{array}$ \\
\hline Forgot about appointment & $20(27)$ & $3(\mathrm{II})$ \\
Too psychiatrically ill to attend & $10(14)$ & $4(14)$ \\
Reported clerical error & $8(\mathrm{II})$ & $4(14)$ \\
Other commitment took priority & $6(8)$ & $3(\mathrm{II})$ \\
Overslept & $6(8)$ & $\mathrm{I}(3)$ \\
Unhappy with treatment & $6(8)$ & $\mathrm{I}(3)$ \\
'Couldn't be bothered' & $5(7)$ & $\mathrm{I}(3)$ \\
No need to attend as no problem & $5(7)$ & $0(0)$ \\
Lost appointment card & $3(4)$ & $\mathrm{I}(3)$ \\
Travel problem & $3(4)$ & $0(0)$ \\
Felt better & $\mathrm{I}(\mathrm{I})$ & $\mathrm{I}(3)$ \\
Too physically ill to attend & $\mathrm{I}(\mathrm{I})$ & $\mathrm{I}(3)$ \\
Unhappy with psychiatric referral & $0(0)$ & $5(17)$ \\
Afraid of admission & $0(0)$ & $3(\mathrm{II})$ \\
Bad weather prevented attendance & $0(0)$ & $\mathrm{I}(3)$ \\
\hline
\end{tabular}

The relatively low response rates detailed in Table 1 may have introduced non-response bias in the data obtained. Given that the study was of people who were non-adherent with their psychiatric management plan, non-response was predicted to be a potential problem from the start. We therefore sought to minimise this source of error by repeated attempts to contact the subjects and the use of face-to-face interviews. This approach seems to have had some success in that the response rates achieved here are higher than those reported for any other published study of mental health or non-mental health outpatient non-attendance we have located, for example, $40 \%$ for psychiatric attenders and non-attenders (Hills \& Alexander, 1990 ) and $43 \%$ for non-attenders at ear, nose and throat, gastroenterology (Lloyd et al, 1993) and ophthalmology clinics (Potamitis et al, 1994). We were also able to collect basic socio-demographic data and full outcome data on all subjects from the case notes.

\section{Follow-up non-attendance}

The results of this study suggest that nonattendance at psychiatric follow-up appointments is of important clinical significance. Those who failed to attend were more unwell and more socially impaired than those who kept appointments. Nonattendance at recruitment predicted further non-attendance, drop-out from out-patient services and subsequent admission. There was no evidence from the case notes that out-patient services were being substituted for by other community psychiatric services for non-attenders. Our data suggest that the first episode of nonattendance may be an important time to intervene to attempt to prevent loss to

Table 6 Outcome at six and twelve months for attenders and non-attenders at a psychiatric out-patient clinic

\begin{tabular}{|c|c|c|c|c|c|c|c|c|}
\hline Study group & $\begin{array}{c}\text { Outcome } \\
\text { period (months) }\end{array}$ & $\begin{array}{l}\text { Attending, no } \\
\text { admission }\end{array}$ & $\begin{array}{l}\text { Attending, } \\
\text { admission }\end{array}$ & $\begin{array}{l}\text { Not attending, } \\
\text { no admission }\end{array}$ & $\begin{array}{l}\text { Not attending, } \\
\text { admission }\end{array}$ & $\begin{array}{l}\text { Discharged, } \\
\text { no admission }\end{array}$ & $\begin{array}{l}\text { Discharged, } \\
\text { admission }\end{array}$ & Died \\
\hline New patient non-attenders, & 6 & $4(7)$ & $0(0)$ & $9(15)$ & I (2) & $44(75)$ & I (2) & $0(0)$ \\
\hline$n=59(\%)$ & 12 & $8(14)$ & $0(0)$ & $3(5)$ & I (2) & $46(78)$ & I (2) & $0(0)$ \\
\hline New patient attenders, & 6 & $17(42)$ & I (2) & $I(2)$ & $0(0)$ & $22(54)$ & $0(0)$ & $0(0)$ \\
\hline$n=4 \mid(\%)$ & 12 & $17(42)$ & $2(5)$ & $0(0)$ & $0(0)$ & $22(54)$ & $0(0)$ & $0(0)$ \\
\hline Follow-up non-attenders, & 6 & $41(32)$ & $6(5)$ & $19(15)$ & $17(13)$ & $44(34)$ & $I(I)$ & I (I) \\
\hline$n=129(\%)$ & 12 & $36(28)$ & $10(8)$ & $3(2)$ & $29(23)$ & $46(36)$ & $3(2)$ & $2(2)$ \\
\hline Follow-up attenders, & 6 & $69(5 \mathrm{I})$ & $23(17)$ & $4(3)$ & $0(0)$ & $39(29)$ & $0(0)$ & I (I) \\
\hline$n=136(\%)$ & 12 & 71 (52) & $26(19)$ & $2(2)$ & $I(I)$ & $35(26)$ & $0(0)$ & $\mathrm{I}(\mathrm{I})$ \\
\hline
\end{tabular}


follow-up of those with serious mental illnesses and that sending repeat appointments to non-attenders may be an insufficient response.

\section{New referrals compared with follow-up patients}

The data from this study confirm that new referrals for psychiatric out-patient assessment have a different profile of mental disorder compared with the follow-up population, with a predominance of nonpsychotic disorder of lower severity. These findings are in line with Johnson's (1973) report that the majority of new referrals have a diagnosis of depression or anxiety but that those who remain under the care of psychiatric services have serious mental illness such as schizophrenia and bipolar affective disorder. In contrast to previous studies we found no evidence that those with diagnoses of personality disorder and neuroses were less likely to attend (Lister \& Scott, 1988; Verbov, 1992), although our study was not designed with sufficient statistical power specifically to address this hypothesis.

\section{Reasons for non-attendance}

Despite exhaustive inquiries we were unable to trace a substantial number of nonattenders $(27 / 188,14 \%)$. For new patients this might reflect inappropriate referral, but the untraceable follow-up population is more worrying as it may represent a mobile group with serious mental health problems who are not receiving appropriate community psychiatric follow-up. This finding suggests a high rate of inaccuracy of records in hospitals, general practices and social services and that it might be useful to check patients' addresses at each contact.

Twice as many of the follow-up nonattenders said that they had forgotten their appointment compared with the proportion reported by other medical outpatients (Verbov, 1992; Potamitis et al, 1994). Psychiatric out-patients might therefore benefit from a system of active reminding, a strategy which has been reported to improve attendance (Rusius, 1995). New referrals who do not agree to referral have been reported to be less likely to attend (Koch \& Gillis, 1991; Grunebaum et al, 1996) and our data support this. As expected, we found a very high unemployment rate among all psychiatric

\section{CLINICAL IMPLICATIONS}

- This study demonstrates that new patients and follow-up patients in psychiatric clinics are distinct groups with different diagnostic profiles and degree of mental illness. Follow-up patients are more mentally unwell than new patients, and follow-up patients who miss their appointments are more unwell than those who attend. They are also more socially impaired, more socially isolated and they have a higher rate of previous involuntary admission to hospital.

- Follow-up patients who miss an appointment are at a higher risk of drop-out and admission within a 12 -month period.

Clinicians should carefully consider action following non-attendance including the possibility of an alternative management plan such as a community visit rather than a repeat appointment.

\section{LIMITATIONS}

Generalisability may be limited, since the study was carried out in a single inner-city area.

- The study focused on out-patient elements of the service only.

- The response rate was fairly low in some groups studied, but higher than in any previous study.

HELEN KILLASPY, MRCPsych, Department of Psychiatry and Behavioural Sciences, Royal Free and University College Medical School, London; SUBE BANERJEE, MD, Section of Epidemiology and General Practice, Institute of Psychiatry, London; MICHAEL KING, MD, Professor of Psychiatry, Department of Psychiatry and Behavioural Sciences, Royal Free and University College Medical School, London; MARGARET LLOYD, MD, Department of Primary Care and Population Sciences, Royal Free and University College Medical School, London

Correspondence: Dr Sube Banerjee, Section of Epidemiology and General Practice, Institute of Psychiatry, De Crespigny Park, London SE5 8AF

(First received 30 November 1998, resubmitted I3 July 1999, accepted 27 July 1999)

out-patients; non-attendance was not, therefore, likely to be associated with difficulty in taking time off work. Clerical error has been shown to account for up to $45 \%$ of missed appointments in other hospital specialities (Verbov, 1992; Potamitis et al, 1994) but in our population it was reported to account for $12 \%$ of non-attendance at most.

This study suggests that the group of patients who are at particular risk of loss to follow-up and relapse are likely to have a diagnosis of schizophrenia, schizoaffective disorder or bipolar affective illness. They have more severe current disorder and are likely to be socially isolated, often with only professionals for support.
Their psychiatric symptoms seem to suggest three main ways in which they might contribute to non-attendance: (a) active symptomatology such as paranoid delusions or feeling too depressed to get up; (b) negative symptoms such as apathy and reduced organisational skills; and (c) lack of insight.

\section{ACKNOWLEDGEMENTS}

We thank all the patients who took part in the study, and the out-patient and secretarial staff of the Royal Free Hospital. This study was funded by the NHS Executive, North Thames Regional Office, Research and Development Division. 


\section{REFERENCES}

Grunebaum, M., Luber, P., Callahan, M., et al (1996) Predictors of missed appointments for psychiatric consultations in a primary care clinic. Psychiatric Services, 47, 848-852.

Hillis, G. \& Alexander, D. A. (1990) Rejection of psychiatric treatment. Psychiatric Bulletin, 14, 149-150.

Johnson, D. A. W. (1973) An analysis of outpatient services. British Journal of Psychiatry, 122, 30I-306.

Johnson, S. \& Lelliott, P. (1997) Mental health services in London: evidence from research and routine data. In London's Mental Health (eds S. Johnson, R. Ramsey, G. Thornicroft, et al). London: King's Fund.

Jones, D. T. (1987) A survey of hospital outpatient referral rates, Wales, 1985. British Medical Journal, 295, 734-736.

Koch, A. \& Gillis, L. S. (1991) Non-attendance of psychiatric out-patients. South African Medical Journal, 80, 289-291.
Krawiecka, M., Goldberg, D. \& Vaughan, M. (1977) A standardized psychiatric assessment scale for rating chronic psychotic patients. Acta Psychiatrica Scandinavica, 66, 299-308.

Lister, E. S. \& Scott, J. (1988) Did not attend: characteristics of patients who fail to attend their first appointment at a psychiatric out-patient clinic. Health Trends, 20, 65-66.

Lloyd, M., Bradford, C. \& Webb, S. (1993) Nonattendance at out-patient clinics: is it related to the referral process? Family Practice, 10, III-117.

Marks, I. (1986) Work and Social Adjustment Scale, Behavioural Psychotherapy. Bristol: John Wright.

McGlade, K. J., Bradley, T., Murphy, G. J., et al (1988) Referrals to hospital by general practitioners: a study of compliance and communication. British Medical Journal, 297. $1246-1248$

Potamitis, T., Chell, P. B., Jones, H. S., et al (1994) Non-attendance at ophthalmology out-patient clinics. Journal of the Royal Society of Medicine, 87, 59|-593.
Ritchie, J. H., Dick, D. \& Lingham, R. (1994) The Report of the Inquiry into the Care and Treatment of Christopher Clunis. London: HMSO.

Rusius, C.W. (1995) Improving out-patient attendance using postal appointment reminders. Psychiatric Bulletin, 19, 291-292.

Steering Committee of the Confidential Inquiry into Homicides and Suicides by Mentally III People (1996) Report of the Confidential Inquiry into Homicides and Suicides by Mentally III People. London: Royal College of Psychiatrists.

Verbov, J. (1992) Why 100 patients failed to keep an out-patient appointment - audit in a dermatology department. Journal of the Royal Society of Medicine, $\mathbf{8 5}$ 277-278.

World Health Organization (1992) International Classification of Diseases (ICD-10). Geneva: WHO. 